\title{
PERCEPÇÃO DE MULHERES EM SITUAÇÃO DE VIOLÊNCIA SOBRE O SUPORTE E APOIO RECEBIDO EM SEU CONTEXTO SOCIAL ${ }^{1}$
}

\author{
Liliane Nascimento de Santi², Ana Márcia Spanó Nakano³, Angelina Lettiere ${ }^{4}$
}

\begin{abstract}
${ }^{1}$ Artigo extraído do projeto financiado pela Fundação de Apoio Pesquisa Estado São Paulo, processo no $2004 / 04670$.
${ }^{2}$ Doutora em Enfermagem em Saúde Pública. Professora Adjunto do Departamento de Odontologia Social da Universidade Federal do Pará. Pará, Brasil. E-mail lilicdribeirao@hotmail.com

${ }^{3}$ Doutora em Enfermagem. Professora Associado do Departamento de Enfermagem Materno-Infantil e Saúde Pública da Escola de Enfermagem de Ribeirão Preto (EERP) da Universidade de São Paulo (USP). São Paulo, Brasil. E-mail nakano@eerp.usp.br

${ }^{4}$ Pós-graduanda do Programa de Enfermagem em Saúde Pública da EERP/USP. São Paulo Brasil. E-mail angelina.lettiere@ usp.br
\end{abstract}

RESUMO: Buscamos identificar a percepção das mulheres em situação de violência sobre o suporte e o apoio recebido em seu contexto social, particularmente, dos recursos institucionalizados de combate à violência contra a mulher. Estudo descritivo e exploratório de abordagem qualitativa desenvolvido no Instituto Médico Legal de Ribeirão Preto. Foram entrevistadas 57 mulheres, vítimas de violência doméstica do tipo lesão corporal dolosa, e os dados analisados pela modalidade temática. A busca por ajuda ocorre no seu próprio meio social, junto à família e amigos. A utilização dos serviços de saúde depende da percepção da gravidade do estado de saúde e nem sempre resulta em resposta adequada às demandas das mulheres. Na justiça, a realidade de desamparo e descrença aponta para desarticulação e inoperância das instituições sociais de suporte às vítimas. Para o atendimento integral e humanizado, as ações devem ir além de protocolos de ação, pensando em estratégias de prevenção e redução de violência.

DESCRITORES: Saúde pública. Violência doméstica. Identidade de gênero.

\section{DOMESTICALLY ABUSED BRAZILIAN WOMEN'S PERCEPTIONS ABOUT SUPPORT AND RECEIVED SUPPORT IN ITS SOCIAL CONTEXT}

\begin{abstract}
We seek to identify the perceptions of women in situations of violence concerning the support and assistance received in its social context, particularly, the institutionalized resources to combat violence against women. A descriptive exploratory qualitative approach was developed at the Institute of Forensic Medicine in Ribeirão Preto, Brazil. We interviewed 57 women victims of aggravated assault domestic violence and analyzed the results thematically. The search for help occurs in its own social environment, together with family and friends. The use of health services depends on the perception of the severity of the condition and does not always result in adequate responses to these women's demands. In justice, the reality of helplessness and disbelief points to dislocation and failure of available social support institutions for victims. For integral and humanized care, the actions should go beyond the protocols of action, thinking of prevention and reduced violence strategies.
\end{abstract}

DESCRIPTORS: Public health. Domestic violence. Gender identity.

\section{LA PERCEPCIÓN DE LAS MUJERES VÍCTIMAS DE VIOLENCIA SOBRE LA ASISTENCIA Y EL APOYO RECIBIDO EN SU CONTEXTO SOCIAL}

\begin{abstract}
RESUMEN: El objetivo del estudio es identificar la percepción de las mujeres víctimas de violencia, sobre el apoyo y la asistencia recibida en su contexto social, y en particular, los recursos institucionalizados para combatir la violencia contra la mujer. Es un estudio exploratorio descriptivo, con enfoque cualitativo, desarrollado en el Instituto Médico Legal de Ribeirão Preto. Se entrevistaron 57 mujeres víctimas de violencia doméstica con lesión corporal dolosa. El análisis de los datos se hizo según la modalidad temática. La búsqueda de ayuda viene de su propio entorno social, con la familia y amigos. El uso de los servicios de salud depende de la percepción de la gravedad del estado de salud y no siempre resulta en una respuesta adecuada. En la justicia, la realidad de desamparo y poca credibilidad muestran la desarticulación e inoperancia de las instituciones en el apoyo a las víctimas. Para la atención integral y humanizada, las acciones deberían ir más allá de los protocolos de acción, pensando en estrategias para prevenir y reducir la violencia.
\end{abstract}

DESCRIPTORES: Salud pública. Violencia domestica. Identidad de género. 


\section{INTRODUÇÃO}

A violência tem merecido lugar de destaque entre as preocupações cotidianas, gerando políticas governamentais em diversos países do mundo. Para a Organização Pan-Americana de Saúde, a violência adquiriu um caráter endêmico e se converteu em um problema de saúde pública, devido ao número de vítimas e à magnitude de seqüelas orgânicas e emocionais que produz. ${ }^{1}$ Neste sentido, a Organização Mundial da Saúde (OMS), ao publicar, em 2002, o Relatório Mundial sobre a Violência e Saúde torna público o problema da violência, definindo-o como: "uso intencional de força ou poder, através de ameaça ou agressão real, contra si mesmo, outra pessoa ou contra um grupo ou comunidade, que resulta ou tem grande probabilidade de resultar em ferimentos, morte, prejuízos psicológicos, problemas de desenvolvimento ou privação". $2: 5$

Diante do complexo fenômeno da violência, presente no espaço social, encontra-se a violência contra a mulher. O primeiro documento internacional de direito humano que aborda esta violência foi aprovado em 1993, na Assembléia Geral das Nações Unidas. Esse documento define violência contra a mulher como qualquer ato de violência baseado no gênero que resulta, ou tenha probabilidade de resultar, dano ou sofrimento físico, sexual e psicológico, incluindo ameaça, coação ou privação arbitrária de liberdade, na vida pública ou privada. ${ }^{3}$

A violência praticada contra a mulher pode estar presente em todos os âmbitos da vida e se manifestar sob diferentes formas e inúmeras circunstâncias. Neste contexto, dentre as diversas situações de violência das quais as mulheres são vítimas, destacam-se, mais freqüentemente, aquelas ocorridas no espaço socialmente estabelecido para as mulheres: o espaço privado, a família e o domicílio. ${ }^{4}$ Desta forma, a violência doméstica refere-se a todas as formas de violência e aos comportamentos dominantes praticados no âmbito familiar. ${ }^{5}$

Vale considerar que a violência doméstica, embora presente na maioria das sociedades, é freqüentemente invisível, sendo, por vezes, aceita socialmente como "normal", ou seja, como uma situação esperada e costumeira. ${ }^{5}$ Frente a esta realidade, concordamos que não se pode aceitar a violência como fato corriqueiro e, particularmente, no campo da saúde, não se deve reduzir a atenção apenas a suas conseqüências à saúde, assim, a responsabilidade dos profissionais e cientistas desta área, em conjunção com outros setores da sociedade, é de que se preocupem com a prevenção e intervenham, posicionando-se no combate à violência. ${ }^{6}$

É neste contexto que, a partir dos anos 80, os avanços na implementação de ações de suporte à mulher teve como marco importante a preocupação de dar visibilidade ao fenômeno. Nesta perspectiva, um ativo movimento feminista tem reivindicado o direito à saúde e o enfrentamento à violência contra a mulher, os quais culminaram com significativas alterações no estatuto legal da mulher na família e na sociedade, ampliando, assim, seus direitos civis e sociais na Constituição de 1988. Estes avanços foram forças decisivas para impulsionar ações preventivas e de suporte à mulher, apresentando importante conexão com a saúde. ${ }^{7-8}$

Estas reivindicações contribuíram para a criação de serviços específicos como as Delegacias de Defesa da Mulher (DDM), as Casas-Abrigo e os Centros de Atendimento Multiprofissionais, focando, principalmente, a violência física e sexual, cometida por parceiros ou ex-parceiros, além de importantes mudanças na legislação nacional. ${ }^{9}$

No entanto, a atenção às mulheres em situação de violência ocorre de maneira fragmentada e pontual. No que se refere aos serviços, estes não estão preparados para atendê-las de maneira integral. De um modo geral, as vítimas de violência percorrem vários caminhos, em decorrência de um processo desarticulado dos serviços. Em relação à assistência, nota-se que o profissional de saúde cria uma fragmentação da ação e do objeto de trabalho. Neste caso, o indivíduo reduz a abordagem da saúde/doença aos saberes biomédicos desarticulados do contexto biopsicossocial. ${ }^{10}$

Nesta perspectiva, o acolhimento da mulher em situação de violência é um grande desafio, que se impõe diante desta realidade, requerendo esforços conjuntos de todos os setores sociais. Frente a este cenário, atuando no Instituto Médico Legal de Ribeirão Preto, onde desenvolvemos exame de corpo de delito de vítimas com trauma facial, deparamo-nos com a realidade concreta da violência e de suas repercussões para a saúde da mulher. Observações não sistematizadas evidenciam que, de modo geral, os serviços pouco respondem as necessidades prementes das vítimas, ou seja, as ações são pontuais, fragmentadas, sem compromisso de continuidade na atenção à vítima, tanto nos aspectos de reabilitação física e emocional quanto nos de reabilitação social e jurídica.

Temos como objetivo identificar a percepção das mulheres, em situação de violência, sobre o suporte e apoio recebido em seu contexto social, 
particularmente, dos recursos institucionalizados de combate à violência contra a mulher.

Acreditamos que o resultado desta pesquisa possa contribuir para que se estabeleçam estratégias de suporte ou de apoio efetivo às mulheres em situação de violência, com base em seu contexto de vida e respeitando seu direito e autonomia de decisão, bem como alertar para necessidade de se construir uma postura profissional e cidadã para desenvolver um trabalho em rede, em conjunção com setores da sociedade, a fim de prestar o atendimento integral e humanizado.

\section{METODOLOGIA}

Trata-se de um estudo descritivo-exploratório de abordagem qualitativa. O cenário do estudo foi o Núcleo de Odontologia Legal do Instituto Médico Legal de Ribeirão Preto.

O universo empírico deste estudo foi composto por todos os casos de mulheres vítimas de violência doméstica, tipo lesão corporal dolosa, que foram atendidas na referida instituição, no período referente a maio de 2005 a outubro de 2006. Neste período, foram atendidas 284 mulheres vítimas de lesão corporal dolosa - crime enquadrado no artigo 129 do Código Penal Brasileiro. Como recorte empírico, foram incluídas apenas as mulheres encaminhadas ao Núcleo de Odontologia Legal deste Instituto, ou seja, as que sofreram traumas faciais de alguma natureza, o que corresponde a 57 mulheres do total de casos atendidos.

A coleta dos dados foi realizada nas dependências do IML/RP em dois momentos distintos: no primeiro dia do exame pericial, quando da requisição do exame de corpo de delito para averiguação do crime de lesão corporal dolosa; e no dia do retorno para exame complementar. Desta forma, após serem informadas dos objetivos do estudo, as mulheres foram convidadas para participarem da pesquisa, com o anonimato garantido. Frente ao aceite, assinou-se o Termo de Compromisso Livre e Esclarecido. Vale informar que todos os critérios éticos da Resolução 196/96 do CNS, que trata da pesquisa envolvendo seres humanos, foram obedecidos e o estudo teve aprovação do Comitê de Ética em Pesquisa da Escola de Enfermagem de Ribeirão Preto da Universidade de São Paulo, sob parecer n ${ }^{\circ}$ 0450/2004.

As entrevistas semi-estruturadas foram individuais e gravadas. Para a gravação adotouse a técnica de depoimento pessoal, que permite estimular a pessoa a falar sobre como pensa e sobre o que faz acerca do tema em questão. Isso permite ao pesquisador aprofundar mais os aspectos relativos aos objetivos do estudo, sem ultrapassar a dimensão individual dos relatos para encontrar neles o coletivo. ${ }^{11} \mathrm{O}$ roteiro contemplava dados de identificação dos sujeitos e sobre a percepção do fenômeno, ou seja, o significado da violência e a busca de suporte ou ajuda.

Os dados obtidos nas entrevistas foram transcritos e organizados com base nas orientações metodológicas para análise de conteúdo modalidade temática. Esta técnica "consiste em descobrir os núcleos de sentidos que compõem a comunicação e cuja presença, ou frequência de aparição, pode significar alguma coisa para o objetivo analítico escolhido". ${ }^{2: 131}$

Para a análise dos resultados, foram incorporadas as contribuições teóricas sobre gênero e o conceito de integralidade. A incorporação da noção de gênero traz uma visão relacional à compreensão do problema da violência contra a mulher, em que parte da raiz do problema é a condição de subordinação da mulher na sociedade, sendo esta condição o produto de tensões nos papéis do feminino e do masculino, constituídos social e historicamente. ${ }^{13}$

Na perspectiva da integralidade, as mulheres que buscam ajuda precisam ter suas necessidades reconhecidas para serem adequadamente assistidas. Isso consiste em traduzir e atender, da melhor forma possível, as necessidades, sempre complexas, mas, principalmente, que têm de ser captadas em sua expressão individual. ${ }^{14}$

\section{RESULTADOS E DISCUSSÃO}

O grupo foi composto por 57 mulheres. A análise das características sócioeconômicas dessas mulheres identificou que a média de idade das mulheres foi de 31,5 anos, com uma idade mínima de 19 anos e máxima de 44 anos. Em relação ao estado civil das mulheres, 20 delas $(29,9 \%)$ declaram-se divorciadas. Com parecido percentual, 19 delas $(28,4 \%)$ declaram-se casadas e solteiras. Vivendo em união estável, no momento do atendimento, houve um total de nove mulheres (13,4\%). Quando interrogadas a respeito de sua etnia, a maioria, 45(67,2\%) declarou-se branca; 13 (19,4\%) pardas; e nove $(13,4 \%)$, negras. Quanto à renda, mais da metade das mulheres possuem uma renda familiar inferior a dois salários mínimos.

O perfil sociodemográfico tem sido estudado como um dos fatores associados à violência contra 
a mulher, dentre os quais se destacam: baixo nível socioeconômico, etnia, idade (ser jovem) e o baixo nível de suporte social. ${ }^{15}$

Sobre a violência sofrida, o maior percentual ocorreu dentro da residência, característica que atingiu 41 (61,2\%) mulheres. O agressor era conhecido pela vítima em $89,6 \%$ dos casos, sendo que, dentre eles, 36 (53,7\%) eram maridos e namorados, e $18(26,9 \%)$, eram ex-maridos e ex-namorados das vítimas.

Depreendemos das falas das entrevistadas três categorias temáticas centrais: A exposição da violência sofrida; A busca por serviços de saúde; e A busca pela delegacia.

\section{A exposição da violência sofrida: "vem todo mundo ajudá... dá palpite"}

Em relação à primeira categoria temática, identificamos que, apesar de proteções internacionais, a mulher ainda se encontra em uma posição de vulnerabilidade social. ${ }^{16}$ Assim, na situação de violência, a mulher parece viver uma dupla violência, ou seja, aquela resultante do ato violento em si e a da invasão de sua privacidade pela exposição do ato sofrido como identificado na fala:

[...] depois veio as vizinhas, mas sabe é mais pra saber do causo do que pra me ajudar. Na hora que eu tava levando na cara num pareceu ninguém aqui pra me socorrer (E42).

Desta forma, as consequências da violência contra a mulher, independente da sua forma de manifestação, têm, na vergonha do ato sofrido, uma invasão de sua privacidade e a negação de sua liberdade e integridade e, também, a culpabilidade por não terem sido capazes de resistir suficientemente. ${ }^{17}$ Nesta invasão de privacidade observa-se, através das falas das mulheres deste estudo, que, aos olhos dos outros, o fato de terem sofrido violência se reveste de significados estruturados por um padrão de relações sexuais hierárquicas, no qual a mulher se apresenta por vezes merecedora desta violência. Desta forma, identifica-se que esta atitude configura um reflexo da manutenção de desigualdade e de hierarquias existentes para garantir a obediência e a subalternidade de um sexo em relação ao outro. ${ }^{18}$

Quando meu pai chegou ele queria saber o que eu tinha feito de errado [...]. Quando minha mãe ficou sabendo, tirou eu de lá e fez eu voltar com ele (E1).

Minha mãe queria saber o que eu tinha feito. Num é brinquedo não! A gente apanha e invés dos outros ajudar, a gente toma mais na cara! (E7).
Entretanto, sobre o fato violento, são atribuídas significações sociais que se inserem num cenário de regras de dominação, em que as mulheres são vistas como "coitadinhas", requerendo ser protegida do homem enfurecido, que deve ser contido, em função de seu ímpeto de ser viril e dominador, como descrito na fala a seguir:

[...] ainda bem que nessas horas todo mundo quer fazer alguma coisa, todo mundo tem pena... você vira coitadinha (E36).

Esta condição de inferioridade relatada pelas entrevistadas advém de construções sociais em que valores, crenças e costumes legitimam um padrão de relacionamento assimétrico entre homens e as mulheres. Assim, sua autoridade, longe de ser um atributo biológico, indica um comportamento aprendido, socializado para o exercício da autoridade, e as mulheres, pelo mesmo mecanismo, são submetidas à autoridade. Nesta perspectiva de gênero, dos homens são exigidos os comportamentos masculinos como agressividade, destemor e força, enquanto que das mulheres se exige suavidade, abnegação e obediência. ${ }^{19}$

Neste contexto, a busca por ajuda na família demonstra que os papéis de gênero tradicionais têm grande influência na percepção e reação em situações de violência. Assim, a busca pelo apoio das famílias, anteriormente ao da instituição, é apontada como estratégia de autoproteção, a fim de evitar outra vitimização, uma vez que os membros da família cuidam um do outro. ${ }^{20}$ Esta ação de apoio também foi verificada nas mulheres do nosso estudo, que buscam ajuda, à princípio, em seu próprio meio social mais próximo, sendo importante a participação dada à família e à rede de amigos, como identificado na fala:

[...] quem ajuda a gente nessa hora mesmo é só a família, até mesmo a família do homem que bate na gente num aceita e ajuda a gente (E3).

[...] minha amiga me socorreu, se num fosse ela acho que tava ainda lá (E15).

No entanto, muitas vezes, os conselhos dados por familiares podem ser interpretados de maneira que venha ferir ou piorar o sofrimento já instalado pela situação em si, constituindo-se em um agravo. ${ }^{21}$ É neste sentido que, no conjunto das ações de suporte e ajuda para as mulheres em situação de violência, identificamos desarticulações com o que realmente as mulheres esperam receber, que vai além das conseqüências imediatas dos atos violentos, mas também a compreensão, a solidariedade, a proteção e a melhoria das condições econômicas. 
Eu só queria ficar quietinha ali com minha dor e mesmo assim me levaram para o médico (E36).

Tem hora assim que num sei que é pior fazer [...] assim que nem eu fiz ou se eu tinha que ter ficado lá em casa tomando dos meus remédios mesmo e esperado passar [...] as meninas me trouxeram com tanta disposição, como eu ia fazer (E24).

Frente ao exposto, o que se evidencia é a pluralidade da violência, que não se reduz a marcas no físico, mas produz a anulação de sujeito, além de exposição de espaços e de momentos de grande intimidade e privacidade.

\section{A busca por serviços de saúde: "Como se adiantasse! Lá eles te dão um remédio fajuto e te manda embora"}

A busca por ajuda nos equipamentos sociais depende de como percebem o estado de gravidade do caso. Neste sentido é que elegem quais as providências a serem tomadas quanto ao cuidado à saúde.

Cheguei no hospital muito fraca, sangrava... a cabeça rodava. No outro dia nem precisei de ir assim lá, porque tava só dolorido (E9).

Uma vez fui atendida nas clínicas, mas só quando ele me enfiou a faca, então só adianta ir quando está morrendo. Eu já disse para minha comadre: na hora que eu tiver quase morrendo me leva já pras clínicas (E39).

Me levaram no postinho, mas num era grave. Logo fui embora (E18).

Dentre os serviços de saúde mais procurados pelas mulheres vítimas de violência sexual e doméstica estão os pronto-socorros. Estes locais têm de responder a dois dilemas: perceber/reconhecer a violência sofrida pela mulher, dando credibilidade a uma queixa; e romper com uma recorrente prática de medicalizar os eventos observados. ${ }^{22}$

Neste contexto, sobra a medicalização decorrente da violência, as mulheres tendem a se orientar pela gravidade dos traumas. Observamos que o hospital é o local de escolha quando o estado da vítima é grave. Já o posto de saúde tende a ser utilizado no caso dos traumas leves, ou, até mesmo, é comum a vítima recorrer aos recursos caseiros. Entretanto, outro aspecto a ser considerado sobre os serviços de saúde são as ações do profissional da área, que, em sua maioria, reduzem-se a responder ao que se mostra concreto, em termos dos sinais e sintomas.

Fiquei lá uns dias. Eles me costuraram de novo. Fiquei quase duas semanas, porque num tinha só eu.
Tinha a neném também. Eles cuidaram dela também[...]. Lá eles disseram que se eu sentisse alguma coisa, para eu procurar o postinho (E2).

Nossa! Doía demais, ainda ta doendo, mas lá no posto eles disseram que é assim mesmo. Tenho que ter paciência e esperar que já melhora, passa né e ninguém mais vai vêe (E28).

Desta forma, os casos de violência ficam mais fáceis de serem identificados quando apresentam lesões aparentes. No entanto, quando as queixas são de ordem psicológica e social, as barreiras estruturantes entre a rede de assistência à mulher impedem o fluxo de assistência devida. ${ }^{23}$ Assim, a intervenção na violência contra a mulher só se justifica quando suas conseqüências são percebidas como uma doença caso contrário, a queixa não é considerada parte das ações em saúde, e as conseqüências são referidas a outra ordem do social e/ou do psicológico, desqualificando-as para uma intervenção médica. Frente à prática clínica, observamos que a conduta dos profissionais de saúde é de não acolhimento às necessidades das mulheres, restringindo suas ações a encaminhamentos, o que também nem sempre resulta em resposta adequada às demandas das mulheres.

Entretanto, essa demanda precisa ser tomada como uma questão de saúde, que aguarda uma intervenção adequada, que será determinada baseando-se no modo como a violência doméstica contra a mulher é compreendida e acolhida. ${ }^{13}$

Esta interface entre a violência e os serviços de saúde deve ser pensada através da lógica do SUS, juntamente com outros serviços que constituem a rede de suporte social. Dentro desta lógica, um aspecto merece destaque na discussão sobre a saúde da mulher, principalmente no contexto da violência: a questão da integralidade. Assim, o atendimento integral é considerar a pessoa humana como uma integralidade e não como a fragmentação da visão biomédica, considerando as determinações de ordem sócio-econômica e cultural. ${ }^{10}$

Nesta perspectiva, a integralidade da atenção à saúde inclui duas dimensões de análise: Integralidade focalizada no espaço dos serviços de saúde; o esforço da equipe de traduzir e atender, da melhor forma possível, tais necessidades, sempre complexas, mas, principalmente, que precisam ser captadas em sua expressão individual; e Integralidade ampliada fruto de uma articulação de cada serviço de saúde a uma rede complexa e a outras instituições não necessariamente do setor saúde. ${ }^{14}$ 
A busca pela delegacia: "só perguntam, mas não resolvem"

Alguns aspectos podem abalar a tolerância feminina à violência, levando a mulher a romper com o silêncio e tornar pública a situação de violência vivenciada. A busca pela Delegacia de Defesa das Mulheres, para as mulheres deste estudo, tem sentido de justiça, de punição ao agressor.

Eles vão batendo, achando que tão podendo, que são os gostosão, até que eu disse: Estou indo pra delegacia [...]. Decidi de verdade dar queixa e não tiro mesmo (E60).

Fui primeiro para DDM, então depois no posto, a raiva faz a gente nem sentir dor. É Muita humilhação achar que o filho num é dele (E61).

Neste sentido, as razões que levam as mulheres a denunciarem seus parceiros íntimos, de modo geral, ocorrem pelo receio de novas agressões ou ameaças, e de terem que fazer alguma coisa, para "ferrar" o parceiro ou "botar pra quebrar", para "procurar meus direitos", "tomar atitude" ou "mostrar para ele que eu não sou igual àquelas outras". Vale considerar que a busca por este recurso deve-se ao efeito produzido no contexto familiar da vítima, ou seja, a intervenção policial possibilita a autoproteção e a repreensão da conduta dos parceiros. ${ }^{24}$

Neste contexto, o uso desses serviços se processa através da consciência em situação, ou seja: procuram primeiramente compreender intrinsecamente a violência; depois procuram profissionais, tanto da justiça quanto da saúde; e, também, buscam respaldo na família e/ou amigos de modo a se cuidarem e serem cuidadas, o que lhes parece de maior importância no alívio da dor. ${ }^{25}$ Desta forma, o tempo, transcorrido entre a agressão física ou ameaça sofrida e a decisão feminina de denunciar, é variável, sugerindo reações bem diferentes e denotando esta complexidade do processo vivido pelas mulheres. ${ }^{24}$

Assim, a queixa policial representa em si uma tentativa de ruptura com uma dada configuração do contexto conjugal ou familiar e com determinada auto-imagem da mulher. Neste sentido, ganham forças para retomar a negociação conjugal, agora em posição privilegiada, efetuando, assim, um deslocamento simbólico na posição de cada elemento do par conjugal, invertendo momentaneamente a relação assimétrica entre os gêneros. Para a mulher, a denuncia à polícia significa rompimento de sua parte com a reciprocidade familiar, como resposta às rupturas causadas pelos homens nesse contexto que, por sua vez, remetem à preeminência do grupo familiar em relação à posição da mulher. ${ }^{24}$ Pesam sobre as mulheres, outros valores, de âmbito pessoal e familiar, que as colocam em conflito quanto à decisão tomada.

Eu estava lá na delegacia fazendo queixa contra o homem que eu amo. Mas mesmo assim ele não tinha o direito de fazer isso. Foi muito grave! Me xingar, me ignorar, tudo bem, passa. Agora, um tapa na cara. Ah, não! Doeu! (E50).

Vale considerar que, neste âmbito, a desqualificação da polícia no atendimento à mulher em situação de violência se mostra evidenciada nas falas das mulheres deste estudo. Diferentemente do que poderiam esperar, ou seja, que a queixa fosse o marco de ruptura com sua condição de vítima, esta as coloca frente a uma realidade de desamparo e descrença na justiça social.

A polícia não faz nada, ele foi embora, sumiu, e eu fiquei aqui (E6).

Uma vez eu tentei. Cheguei na delegacia do bairro e eles disseram que eu tinha que ir em outra, aí eu nem fui (E3).

Assim, atrelada à estrutura deficitária e de baixa resolutividade do aparato policial, estudos têm apresentado que a desqualificação da violência contra a mulher pela instituição policial ou jurídica tem impulsionado as mulheres à interrupção dos procedimentos legais, por meio de "suspensão" da queixa. ${ }^{26}$

Desta forma, aborda-se a suspensão da queixa policial por duas perspectivas: o contexto institucional, através do atendimento policial às mulheres, engendrado no âmbito da relação policial-vítima, que permite relativizar a percepção, bastante difundida no senso comum e o universo sociocultural das mulheres que acionam as delegacias, recortadas sob as questões de gênero. ${ }^{24}$

Frente à prática de atendimento policial às mulheres, o que se verifica é que a burocratização do trabalho de investigação deixa os policiais imersos numa rotina de trabalho, tornando-os pouco disponíveis para uma intervenção mediadora. Neste contexto, entre cumprir suas atribuições legais e a necessidade de uma abordagem não policial, para a qual não se sentem preparados, acabam por considerar a abordagem de relações domésticas menos relevantes, o que naturaliza a violência conjugal e banaliza a intervenção sobre ela. ${ }^{24}$

Portanto, é preciso aprofundar a discussão da capacitação dos profissionais frente ao tema, uma vez que a abordagem da violência nos serviços requer um bom conhecimento das referências 
existentes tanto do âmbito jurídico, policial, social, psicológico e das redes de apoio informal, a fim de dar continuidade ao cuidado fortalecendo a busca de alternativas para solucionar o problema.

\section{CONSIDERAÇÕES FINAIS}

No grupo estudado, tal como apresentado em outros estudos, a busca por ajuda ocorre, à princípio, em seu próprio meio social mais próximo, junto à família e à rede de amigos, o que, para elas, por vezes, nem sempre é ajuda, mas uma violência, por se sentir invadida em sua privacidade.

A busca por serviços de saúde depende de como percebem a gravidade de seu estado de saúde, visto que, para elas, estes serviços não resolvem seus problemas, que não se reduzem ao alívio de sinais e sintomas e do que estes consideram por doença. É preciso refletir que é do momento do espaço clínico em que se determina um diagnóstico até o estabelecimento de uma terapêutica que poderá se constituir de um momento de possibilidades de a mulher ser acolhida e também se recuperar na sua condição de vida. Cabe, portanto, aos profissionais de saúde, incluir em suas ações, uma perspectiva de promoção do indivíduo, em todas as dimensões possíveis, através de ações socioeducativas.

Depreendemos, também, a realidade de desamparo e descrença na justiça social. As mulheres procuram a delegacia da mulher em busca da punição do agressor, e isso corrobora para aumentar a ilusão em torno dos atos violentos, como um simples produto de descontrole, anormalidade, entre outras características imputadas ao agressor de um lado e a incapacidade e passividade da vítima de outro.

Nem todas as mulheres do estudo foram beneficiadas pela Lei Maria da Penha, somente as entrevistadas em 2006, mas, mesmo assim, a efetividade prática da mesma não foi observada, pois ela afetou mais a realização do flagrante e a futura punição do agressor. Observações empíricas na rotina dos serviços, após a Lei ter sido sancionada, diminuiu consideravelmente o número de casos de mulheres para fazer o exame de corpo de delito no IML. Frente a esta realidade, ficam as questões: será que o poder da Lei foi tão forte que os agressores não agridem mais, ou será que a "Lei Maria da Penha" silenciou ainda mais as mulheres? Em que medida o respaldo legal é o suficiente para atender as necessidades destas mulheres vítimas de violência?
A análise dos resultados deste estudo nos coloca frente a uma realidade de desarticulação e de inoperância das instituições sociais de suporte a mulheres vítimas de violência. Entendemos que é necessário, para proporcionar cuidados mais efetivos às vítimas de violência, pensar-se em estratégias que incluam um atendimento multidisciplinar e a conjunção de setores da sociedade a fim de prestar o atendimento integral e humanizado, além de estratégias para a prevenção e redução de ocorrência de episódios de violência. Assim, a mudança deste cenário implica uma importante estratégia em dar voz às mulheres em situação de violência, para que, com base em seu conhecimento, valores e vivências, traduzam as suas reais necessidades quando buscam por apoio e suporte das instituições.

\section{REFERÊNCIAS}

1. Organização Pan-Americana da Saúde. Sociedad, violencia y salud. Washington (US): OPAS; 1996.

2. Krug EG, Dahlberg LL, Mercy JA, Zwi AB, Lozano $\mathrm{R}$, editors. World report on violence and health. Geneva (CH): World Health Organization; 2002.

3. United Nations. Declaration on the elimination of violence against women. General Assembly Resolution $n^{\circ}$. A/RES/48/104 of 20 December 1993. Geneva; 1993.

4. Giffin K. Violência de gênero, sexualidade e saúde. Cad Saúde Pública.1994; 10(supl 1):146-55.

5. World Health Organization. Multi-country study on women's health and domestic violence against women. Geneva $(\mathrm{CH})$ : World Health Organization; 2005.

6. Schraiber LB, D'Oliveira AFPL, Couto MT. Violência e saúde: estudos científicos recentes. Rev Saúde Pública. 2006; 40(Esp):112-20.

7. Minayo MCS. A violência social sob a perspectiva da saúde pública. Cad Saúde Pública. 1994; 10(supl 1):7-18.

8. Oliveira EM. Violência contra a mulher: uma questão de gênero. Acta Paul Enferm. 2000; 13(Esp):171-80.

9. Barsted LAL. Uma vida sem violência é direito nosso. Propostas de ação contra a violência intrafamiliar no Brasil. Brasília (DF): Secretaria Nacional dos Direitos Humanos/ Ministério da Justiça; 1998.

10. Lacerda E. O SUS e o controle social: guia de referência para conselheiros municipais. Brasília (DF): Ministério da Saúde; 1998.

11. Rigotto RM. As técnicas e relatos orais e o estudo das representações sociais em saúde. Ciênc Saúde Colet. 1998 Jan; 3(1):116-29.

12. Bardin L. Análise de conteúdo. Lisboa (PT): Edições 70; 2009. 
13. Schraiber LB, D' Oliveira AFPL. A violência contra mulheres: interfaces com a saúde. Interface. 1999 Ago; 3(5):11-6.

14. Cecílio LCO. As necessidades de saúde como conceito estruturante na luta pela integralidade e eqüidade na atenção em saúde. In: Pinheiro R, Mattos RA, organizadores. Os sentidos da integralidade na atenção e no cuidado à saúde. Rio de Janeiro (RJ): IMS/UERJ-CEPESC - ABRASCO; 2006. p.11-180.

15. Durad JG. Gestação e violência: estudo com usuárias de serviços públicos de saúde da Grande São Paulo [dissertação]. São Paulo (SP): Universidade de São Paulo, Faculdade de Medicina; 2005.

16. Deslandes SF, Gomes R, Silva CMFP. Caracterização dos casos de violência doméstica contra a mulher atendida em dois hospitais públicos do Rio de Janeiro. Cad Saúde Pública. 2000 Jan-Mar; 16(1):129-37

17. Gomes R, Minayo MCS, Silva CFR. Violência contra a mulher: uma questão transcultural e transnacional das relações de gênero. In: Ministério da Saúde (BR). Impacto da violência na saúde dos brasileiros. Brasília (DF): Secretaria de Vigilância em Saúde, Ministério da Saúde; 2005. p. 117-40.

18. Corrêa MSM. Violência de mulheres em condições de violência conjugal [dissertação]. Salvador (BA): Universidade Federal da Bahia, Escola de Enfermagem; 2000.

19. Diniz NMF, Lopes RLM, Gesteira MA, Alves SLB, Gomes NP. Violência conjugal: vivências expressas em discursos masculinos. Rev Esc Enferm USP. 2003 Jun; 37(2):81-8.

20. Snow DL, Swan SC. The development of a theory of women's use of violence in intimate relationships. Violence Against Women. 2006 Nov; 12(11):1026-45

21. Morrison KE, Luchok KJ, Richter DL, Parra-Medina D. Factors influencing help-seeking from informal networks among African American victims of intimate partner violence. J Interpers Violence. 2006 Nov; 21(11):1493-511.

22. Oliveira EM, Barbosa RM, Moura AAVM, Kossel $\mathrm{K}$, Morelli K, Botelho LFF, et al. Atendimento às mulheres vítimas de violência sexual: um estudo qualitativo. Rev Saúde Pública. 2005 Jun; 39(3):376-82.

23. Rotania AA, Dias IMV, Sousa KV, Wolff LR, Reis LB, Tyrrel MAR. Violência contra a mulher: o perigo mora da porta para dentro. Esc Anna Nery Rev Enferm. 2003 Jan; 7(1):114-25.

24. Brandão ER. Renunciantes de direitos? A problemática do enfrentamento público da violência contra a mulher: o caso da delegacia da mulher. Physis. 2006; 16(2):207-31

25. Stenius VMK, Veysey BM. It's the little things. J Interpers Violence. 2005 Oct; 20(10):1155-74.

26. Brandão ER. Violência conjugal e o recurso feminino à polícia. In: Bruschini $\mathrm{C}$, Holanda $\mathrm{HB}$, organizadores. Horizontes plurais. Estudos de gênero no Brasil. Rio de Janeiro (RJ): Fundação Carlos Chagas; 1998. p.51-84. 